\title{
CHILDREN PAIN DURING DENTAL TREATMENT
}

\author{
${ }^{1}$ Jiř́i Marěs, ${ }^{1}$ Marie Hesová, ${ }^{2}$ Hana Skalská, ${ }^{3}$ Věra Hubková, ${ }^{3}$ Romana Chmelařová \\ ${ }^{1}$ Department of Social Medicine, Charles University, Faculty of Medicine, Hradec Králové; \\ (Head: doc. PhDr. J. Mareš, CSc.) \\ ${ }^{2}$ Department of General Information Science, University of Education, Hradec Králové; \\ (Head: RNDr. et PhDr. A. Slabý, CSc.) \\ ${ }^{3}$ Department of Dentistry, Charles University, Faculty of Medicine, Hradec Králové; \\ (Head: doc. MUDr. V. Hubková, CSc.)
}

\begin{abstract}
Summary: This research work was done on the set of 69 children and adolescents 6-14 years old at the children's department of the dental clinic, university hospital in Hradec Králové. We found their expectancy of dental pain inadequate to reality: 67 $\%$ children overestimated expected pain, $12 \%$ underestimated it. It does not see that children feelings prior to very performance would signalize in advance how much unpleasant or painful the dental procedure is going to be. We have not found any significant difference in either understanding the instruction or sticking to them, or general cooperation of children. The average time interval of dental procedures fluctuated between 18 and 40 minutes, children were not given any anesthetics (with exception of two cases of extractions) which could be one of the causes of distress. From all the chidren $35 \%$ experienced pain in the dental chair and were able to assess it by VAS and verbally characterize its quality. According to the view of children assessing the subjectively experienced pain intensity there exist two types of dental procedures: the first type being represented by painless but demanding patience procedures, the second group of painful treatment (making fillings or extractions). There were no statistical difference between girls and boys in their experiencing pain but there was some difference between girls and boys as went for an approach of health workers: these much more often tried to support girls.
\end{abstract}

Key words: Child; Adolescent; Dental treatment; Distress; Pain intensity; Pain quality; Expectancy of pain; Social support

\section{Chalange}

Dental treatment represent for most of our population quite an unpleasant and sometimes even uneasy matter. This attitude is being established and fixated by both the health workers and parents or non-professional public, as well. The painfulness of some dental treatment with negative emotional experience following some treatment are being much talked about ever since the childhood. There exist only few studies, which establish the ways how the children experience and manage various types of dental treatment. Experience of children fear from treatment procedures and strategies of coping with the stress situations in dentistry have already been described (3), as was the experience of anxiety and pain caused by dental treatment $(1,2,4,5)$. This study of ours tries to answer the question if dental treatment typology according to demands and painfulness of treatment procedures for a child patient can be created, and if so, how these different types of dental treatment are experienced by children.

\section{Set}

Altogether 69 children within the age span 6 to 14 years who attended Department of paediatric dentistry of
University Hospital in Hradec Králové were involved. From this number there were 34 boys (49\%) and 35 girls (51\%). Dental care was demanded from various reasons: preventive check-ups, fissure sealing, making filling and even extractions. This set has not been collected randomizely; inquiry was done one afternoon every 2 weeks. Only those children who attended the department mentioned above within 3 months period were involved.

As far as the sex of children is concerned, this set of ours is relatively homogenous. Chi-square test showed that boys and girls did not differ even in age stratification (value of chi-square criterion was $0,1957, \mathrm{p}=0,9068$ ).

\section{Methods}

In our research we used standardized interview, which followed an original questionnaire. Prior to the children questioning an agreement of parents, or in older children also their agreement, was obtained. The cooperation was refused by 1 child only, though his parents had agreed.

Interview was taking place in the waiting room and was done by an experienced high school graduate. Before a child entered the dental office we investigated: mental conditions (what are his/her usual feelings when attending 
the dentist, what are his/her feelings today), anticipation (what is he/she expecting to be done by dentist and what pain does he/she expect).

After treatment accomplished the interview went on. We searched for the actual pain experience intensity and quality, strategy usually spontaneously used by children to manage pain and also a degree of support from the health workers (how much doctor and nurse tried to help him/her in pain managing).

The health workers were asked to identify the person who had actually treated (doctor, medical student), then to elucidate the character of treatment, state the length of treatment and assess the level of child cooperation.

Most of the followed variables were rated within the five level scale. In addition, the actual psychic state was further assessed according to nine level range of a sketched child face from joy to crying. Correlation of verbal and picture methods for finding out the actual psychic state was higher (Spearman's ro reached $0,61, \mathrm{p}<0,05$ ). The pain intesity was evaluated by children with help of visual analogue scale.

From statistical methods mostly non-parametric procedures: Chi square test, Mann-Whitney's test, Spearman's coefficient of rank correlation.

\section{Aims and hypotheses}

The main goal of this study was to describe and analyse mutual relations among these following variables: sex, age, type of treatment, children experience of stress situation, intensity and quality of children pain, pain expected, and pain experienced. Then we wanted to create the typology of dental treatment from the view of their painfulness for children and to map time demands of individual types of dental treatment and correlate these demands to experienced paedodontists and dental students.

\section{Hypotheses:}

$\mathrm{H}_{1}$ : Boys and girls will differ according to ways of experiencing and mastering the dental stress situations. Girls are more emotional and thus they will have less favourite indices.

$\mathrm{H}_{2}$ : Boys and girls will not differ in types of treatment. Dental disorders bringing children into the dental office do not depend on sex.

$\mathrm{H}_{3}$ : Children (regardless to sex) will differ in types of treatment according to their age. Each age group has its own sphere of dental disorders.

$\mathrm{H}_{4}$ : Individual dental treatment can be classified into four groups according to demands and painfulness for the patient. These groups will differ in their time demands, experienced pain intensity, chidlren's going through the whole situation, degree of cooperation of children and social support provided by dental staff.

$\mathrm{H}_{5}$ : Pain expectations of children prior to dental treatment will not be adequate to the pain really experienced.
Most children will overestimate the pain, minority of them will undervaluate it and only a very small number of children will be correct in their expectations. Adequacy of the pain expected and that experienced will depend on the type of treatment, which means on the dental disorders bringing the child in dental office.

\section{Results}

First we would like to point out the differences between boys and girls in their experiencing the dental treatment and their ways of coping with stress situations on the dental chair. Details are given in Tab 1.

Tab. 1: Relation of sex to selected characteristics of children experiencing and behaving.

\begin{tabular}{|l|c|c|}
\hline $\begin{array}{l}\text { child } \\
\text { versus }\end{array}$ & $\begin{array}{l}\text { sex chi-square } \\
\text { criterion level }\end{array}$ & $\begin{array}{c}\text { statistical } \\
\text { significance }\end{array}$ \\
\hline $\begin{array}{l}\text { usual feelings } \\
\text { prior to dental } \\
\text { visit }\end{array}$ & 4,3930 & $0,3554 \quad$ - \\
\hline $\begin{array}{l}\text { actual feelings } \\
\text { in the waiting room } \\
\text { (verbally) }\end{array}$ & 3,4403 & 0,4870 \\
\hline $\begin{array}{l}\text { actual feelings } \\
\text { in the waiting room } \\
\text { (drawing) }\end{array}$ & 6,1764 & 0,5193 \\
\hline $\begin{array}{l}\text { expectations of } \\
\text { unpleasant treatment }\end{array}$ & 0,5301 & 0,9705 \\
\hline $\begin{array}{l}\text { understanding to } \\
\text { health workers } \\
\text { instructions }\end{array}$ & 2,2881 & 0,3185 \\
\hline $\begin{array}{l}\text { following these } \\
\text { instructions }\end{array}$ & 2,0023 & 0,3675 \\
\hline $\begin{array}{l}\text { cooperation with } \\
\text { dental staff }\end{array}$ & 2,3357 & 0,5057 \\
\hline $\begin{array}{l}\text { social support from } \\
\text { health workers }\end{array}$ & 5,7576 & - \\
\hline
\end{tabular}

According to Tab. 1 the first hypothesis has not been confirmed. There are no statistically significant differences either in statements concerning facing the stress situations or in statements of health workers how the children cooperate on the dental chair.

The only statistically significant difference is represented by different behaviour of health workers to girls and 
boys on the dental chair. Significance of this difference was studied also by Fischer exact bilateral test and difference was confirmed $(p=0,0463)$. Health workers more often tried to calm down girls who were thus being helped in coping with the stress situation. In boys the manifestation of health workers' support was rarer. Personnel clearly supposed that „man has to stand something“.

The second hypothesis has been confirmed. There was no difference between boys and girls as concerned the types of dental treatment done (value of chi-square was 0,1269 ; differences unimportant, as $\mathrm{p}=0,7216$ ).

Even the third hypothesis has been confirmed. Children, regardless to sex, differed as for the types of dental treatment procedure (criterion chi-square was 15,8319 and differences were significant on level $\mathrm{p}=0,0147$ ). Different types of treatment used to be also differently time consuming. As the complexity of dental treatment usually grows together with advancing age, also the time demands of treatment were bigger. Differences are statistically significant (chi-quadrate value of 25,4961; difference being statistically significant on level $p=0,0126$ ). Tab. 2 shows how much time a child of certain age category spent on the dental chair.

Tab. 2: Duration of dental treatment with regards to age of children (cumulative frequencies in percentages).

\begin{tabular}{|c|l|l|l|l|l|c|c|}
\hline \multirow{2}{*}{ age categories } & \multicolumn{6}{|c|}{ duration of treatment in minutes } \\
\cline { 2 - 8 } & $0-10$ & $11-20$ & $21-30$ & $31-40$ & $41-50$ & $51-60$ & $61-85$ \\
\hline 6-8 years & 8,7 & 60,9 & 91,3 & 91,3 & 95,6 & 100,0 & - \\
9-11 years & 0 & 36,4 & 59,1 & 77,3 & 77,3 & 95,5 & 100,0 \\
$12-14$ years & 8,3 & 33,3 & 54,1 & 58,3 & 87,5 & 91,7 & 100,0 \\
\hline
\end{tabular}

From Tab. 2 it can be seen that treatment procedures lasted (according to child age) for a relatively long time. This fact thus represents quite an important source of stress for children that is not always being mastered well. In the age category 6-8 years only $61 \%$ of dental treatment were completed within 20 minutes; in category 9-11 years about $60 \%$ of them lasted less than 30 minutes and in the age category $12-14$ years about $60 \%$ of treatment did not take longer than 40 minutes. From these data we can conclude that relatively great part of children stayed in dental chair for much a longer time period. Maximum time interval in our set was 1 hour 25 minutes.

As far as the fourth hypothesis is concerned we postulated four groups of dental treatment (in detail given in tab 3 ). First group was represented by treatment that by dentists are considered as not painful at all. In the second group there belonged long lasting treatment, but also (according to dentists) not painful, though demanding a certain degree of child patience. The third group was represented by restorative procedures that most of the population consider to be painful.
In the last group there were included extractions without or with anesthesia that may be connected with painful experience for children.

Tab. 3: Taxonomy of dental procedures from the view of their possible painfulness.

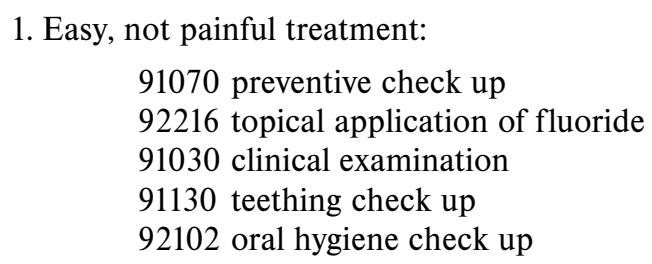

2. Long lasting treatment, not painful but demanding the child patience:

92103 fissure sealing

92130 tooth reconstruction

92204 crown fracture reconstruction

92208 crown fracture reconstruction with composite materials

3. Restorative procedures:

92201 one surface filling

92202 two surfaces filling

92203 three surfaces filling

92241 root canal treatment

92242 root canal treatment of immature permanent tooth

92252 primary teeth restorations

4. Extraction with or without anesthesia:

91510 topical anesthesia

91520 local anesthesia

93101 simple extraction of a loose tooth

93111 extraction of tooth

First we were interested in if children expectations prior to the treatment itself marked a certain treatment, if subjective feelings in advance signalled the discomfort or pain connected with the very dental treatment. As the tab. 4. shows it does not seem to be any significant connection present. Children's feelings did not differ either generally or actually in the waiting room. There were not existing any important differences in children population as for understanding the instructions, their observing, as well as for cooperation of children with health workers, regardless to any dental treatment named within the four groups above, which represented rather a pleasant surprise. Level of child cooperation with health workers in variously painful treatment procedures was tested also by the help of analysis of dispersal but no significant differences were found $(\mathrm{p}=0,5965)$. 
Tab. 4: Experiencing the four types of dental treatment by children

\begin{tabular}{|l|c|c|}
\hline $\begin{array}{l}\text { type of procedure } \\
\text { versus }\end{array}$ & $\begin{array}{c}\text { chi-square } \\
\text { criterion level }\end{array}$ & $\begin{array}{c}\text { statistical } \\
\text { significance }\end{array}$ \\
\hline $\begin{array}{l}\text { common feelings } \\
\text { prior to visit } \\
\text { the dentistry }\end{array}$ & 1,2059 & 0,871 \\
\hline $\begin{array}{l}\text { actual feelings } \\
\text { in the waiting room } \\
\text { (verbally) }\end{array}$ & 2,2785 & 0,6847 \\
\hline $\begin{array}{l}\text { actual feelings } \\
\text { on the waiting room } \\
\text { (drawing) }\end{array}$ & 4,3173 & 0,7426 \\
\hline $\begin{array}{l}\text { health workers } \\
\text { instructions } \\
\text { understanding }\end{array}$ & 2,5700 & 0,2767 \\
\hline $\begin{array}{l}\text { instructions } \\
\text { following }\end{array}$ & 0,9479 & 0,6226 \\
\hline $\begin{array}{l}\text { cooperation with } \\
\text { health workers }\end{array}$ & 2,6177 & 0,4554 \\
\hline $\begin{array}{l}\text { social support form } \\
\text { health workers }\end{array}$ & 0,0523 & - \\
\hline
\end{tabular}

On the contrary, an unpleasant surprise was the fact found on the last line of tab. 4. It informs us that the health workers handled the child always in the same way, regardless to type of treatment . Saying in other words: they did not differentiate when supporting the child and helping him to master the situation, no matter what degree of pain this child may have experienced. The tab. 4 . generally does not seem to support our fourth hypothesis.

Furthermore, we searched for what degree of our proposed typology of dental treatment was actually valid. How much it really differentiated the pain intensity which was being subjectively experienced by children in various types of treatment procedures. Results are given in tab. 5 .

Tab. 5: Differences in intensity of pain experienced according to various types of dental treatment

\begin{tabular}{|l|c|c|c|}
\hline $\begin{array}{l}\text { type of } \\
\text { treatment }\end{array}$ & $\begin{array}{c}\text { No of } \\
\text { children } \\
\text { treated }\end{array}$ & $\begin{array}{c}\text { intensity of } \\
\text { pain } \\
\text { experienced }\end{array}$ & $\begin{array}{c}\text { standard } \\
\text { error } \\
\text { of mean }\end{array}$ \\
\hline 1. (easy) & 19 & 3,31 & 3,57 \\
\hline 2. (long lasting) & 17 & 3,11 & 3,77 \\
\hline 3. (making filling) & 21 & 11,95 & 3,39 \\
\hline 4. (extractions) & 11 & 19,91 & 4,68 \\
\hline
\end{tabular}

Table 5 shows that hypothesis of four types of dental treatment ought to be corrected. Man-Whitney's non-parametric test confirmed this suggestion (see tab. 6).

Tab. 6: Differences between the suggested types of dental treatment concerning the subjectively experienced children pain

\begin{tabular}{|l|c|cc|}
\hline $\begin{array}{l}\text { compared types } \\
\text { of dental treatment }\end{array}$ & $\begin{array}{c}\text { values of T } \\
\text { criterion }\end{array}$ & \multicolumn{2}{|c|}{$\begin{array}{c}\text { statistical } \\
\text { significance }\end{array}$} \\
\hline 1. versus 2. & 38,5 & 0,1351 & - \\
1. versus 3. & 88,0 & 0,0028 & $\mathrm{p}<0,01$ \\
1. versus 4. & 49,5 & 0,0034 & $\mathrm{p}<0,01$ \\
2. versus 3. & 56,0 & 0,0948 & - \\
2. versus 4. & 31,5 & 0,0390 & $\mathrm{p}<0,05$ \\
3. versus 4. & 72,0 & 0,4969 & - \\
\hline
\end{tabular}

As for the children there were not existing four types of painfulness as we supposed, but two only. The first group contained the 1st and 2nd types postulated, second, more painful group of procedures consisted of 2nd type postulated (making filling) and 4th type (tooth extraction).

From the dentists point of view, as well as from the parents' one, there exist several interesting data showing how time consuming the individual types of dental care were (see tab. 7).

Tab. 7: Time demands of individual types of dental treatment.

\begin{tabular}{|l|c|c|c|rc|}
\hline $\begin{array}{l}\text { type of } \\
\text { treatment }\end{array}$ & $\begin{array}{c}\text { No of } \\
\text { children }\end{array}$ & $\begin{array}{c}\text { average time } \\
\text { of treatment } \\
\text { in min. }\end{array}$ & $\begin{array}{c}\text { standard } \\
\text { deviation }\end{array}$ & $\begin{array}{c}\text { time } \\
\text { min max }\end{array}$ \\
\hline 1. (easy) & 19 & 18,42 & 12,02 & 5 & 60 \\
\hline 2. (longlasting) & 17 & 35,88 & 18,58 & 15 & 85 \\
\hline 3. (fillings) & 22 & 40,45 & 13,88 & 20 & 70 \\
\hline 4. (extraction) & 11 & 14,09 & 13,00 & 15 & 60 \\
\hline
\end{tabular}

Data given above are of practical importance as they illustrate the time demands in paediatric dentistry, that rather differ from time demands in adult patients. Nevertheless, the rate tariff of dental treatment considers these differences are non-existent. It is supposed that time needed for an adult cooperative patient and that for a child patient, who usually has to be persuaded to cooperate, is almost identical.

In this connection we have also found quite interesting differences in the length of treatment procedures either by well experienced doctors or by medical students. As our research was conducted in the Teaching Hospital during the morning hours most of the treatment were done by students. The average period of time needed for well-experienced doctors (nine persons) was 25 minutes $(s=14,14)$, for students (59 persons) this time average reached 31,44 minutes 
$(s=17,50)$. If we consider the time interval needed by doctors to represent $100 \%$, then medical students needed about $26 \%$ longer time. Also this finding shows the necessity of special regimen in scoring the educational dental departments. Neither this aspect is being considered by rate tariff.

There remains the fifth hypothesis concerning the relation between pain expected and pain really experienced by children. Pain was expected by 46 children, which means by $67 \%$ of children from this set of ours. Pain really experienced was confirmed by 24 children ( $35 \%$ of our set). The remaining part of the children group did not mention any pain.

It can be generally stated that the correlation between pain expected and that experienced on the dental chair is of a mean tightness. Spearman's ro reaches 0,46 and tightness of this relation is important on level $p<0,05$.

Differences between the expected and real intensity of pain were studied by index $\mathrm{C}_{21}$. This index is characterized by following quotation:

$$
\mathrm{C}_{21}=\frac{\text { pain experienced - pain expected }}{\text { pain expected }} .100(\%)
$$

What are the results?

In $63 \%$ of our children set the expected level of pain has not been confirmed. From all the set $51 \%$ of children experienced the pain smaller than expected. Reality for them was thus more pleasant, less demanding, than they had prepared themselves for, than they had expected.

In $37 \%$ of children the expectations have been confirmed. Altogether $33 \%$ expected that they would not experience any pain and it really was so. Three children (4\%) had estimated the pain intensity well, they experienced the same level of pain as they had expected. In these cases of right estimation we have not found any relation to age (children were 7, 8 and 13 years old).

Generally speaking, the fifth hypothesis has been proved. The expectations were usually far from reality. Most children overestimated the possible pain, then there is a group of realistic estimations and, finally, only a small group of children underestimating the pain.

We have also compared the set of children who underwent painful procedures (3rd type - making filling and 4th type - extractions) with number of children who declared the subjectively felt pain during all types of performances. The painful treatment was done to 32 children, subjective pain experience was stated only by 24 of them. Children most probably experienced the pain in various ways; some of them might be able to modulate it (see the 3rd and 4th types of treatment), other were more sensitive to the whole situation and felt a slight pain even during the treatment of the 1st or 2 nd types that could not, according to dentists, be painful at all.

What does the pain experience depend on? Mostly on the type of treatment, though not explicitly. Correlation with the type of treatment is of a mean tightness (Spearman's ro is equal to $0,43, \mathrm{p}<0,05$ ). There may exist children who undergo even a more serious treatment procedure without the pain experience. On the other hand, there are children experiencing pain even during less serious intervention. Pain experiencing most probably depends also on the child age (connected with the specifics of their dental disorders bringing them to the dental office).

Nevertheless, it doesn't seem that pain experienced would correlate much with emotional states of children in a waiting room, as judged from the children faces drawings (Spearman's ro reaching 0,18 only).

Up to now we were interested in the intensity of the experienced pain only. But also the characteristics of the pain qualities are important. Taking no account of pain expected, the pain experienced during the dental treatment was admitted by 24 children ( $35 \%$ from the whole set). We asked them to describe this pain.

From these $35 \%$ of children $3 \%$ of patients were not able to describe the pain verbally. The remaining $32 \%$ at least tried to. About $10 \%$ stated only the aspect of pain (unpleasant, mild, normal, great, horrible). The remaining $22 \%$ selected some sensoric aspects of pain: it was tingling, hummimg like a humble (2 children), pain was stinging, pricking like the bee sting or the needle prick (4 children), it was stabbing (4 children), it was a pressure pain ( 6 children), burning ( 1 child), scratching ( 1 child), universal pain (1 child).

\section{Conclusions}

This research work has concentrated on relations between the types of dental treatment, children's stress situations experiencing, the expected pain and the pain really experienced. Children from our set were not given any anesthetics (with exception of two cases of extractions). This lack of anesthesia represents the main difference from foreign dental sets of patients (Milgröm et al,1994 and others). In our set of children $6-14$ years old we found:

1) There were no statistical differences between girls and boys either in their interpretations of experiencing stress situation, or in health workers reports concerning the children patients' cooperation.

2) There was some difference between girls and boys as went for an approach of health workers. These much more often tried to support and calm down girls, helping them to master stress situation. In the group of boys the social support from the side of health workers was rarer.

3 ) Boys and girls did not differ from the view of dental treatment performed. Dental complaints bringing children to the doctor did not differ accoridng to sex.

4) Children (regardless to sex) differed in types of treatment done according to age. Each age period brings a special complex of dental complaints. 
5) Dental treatment in one child took tens of minutes. Such a treatment is thus to be considered for a stress situation that may not be succesfully mastered by each child.

6) It does not seem that children feelings prior to very treatment would mark a certain treatment procedure, that their subjective experience would signalize in advance how much unpleasant or painful the dental treatment is going to be. Children feelings do not differ either generally, or in the waiting room. We have not found any significant difference in either understanding the instructions or sticking to them, or general cooperation of children, no matter what type of treatment was done. Our conclusion that health workers did not differentiate in their social support of children should be considered as quite a strucking one. The workers did not change their approach, no matter how painful the treatment might have been.

7) The suggested typology of treatment procedures according to painfulness for a child has not been confirmed. From the view of children who assessed the subjectively experienced pain intensity there exist rather two than four types of dental treatment. The first type is being represented by painless and time consuming procedures , that are also demanding patience and children cooperation. The second group involves more painful treatment - making filling and extractions.

8) This research has brought new, unknown data concerning the time needed for individual types of treatment. The average time interval fluctuated between $18 \mathrm{minu}-$ tes (simple, not painful treatment) and 40 minutes (making filling). Data found illustrate the time demands in paediatric dentistry, being so much different from the adult dentistry. This also is not being followed by rate tariff. This research of ours also confirmed the differences between well experienced doctors and medical students as far as it went for the consumed time. Medical students spend about $26 \%$ time more, than experienced doctors. Neither this situation is being accounted for by rate tariff.

9) Pain expectancy in majority of children was inadequate to reality. Children mostly overestimated expected pain ( $67 \%$ of all the children), the second group expected about the real intensity of pain (37\%) and only $12 \%$ underestimated it.
10) From all the children $35 \%$ experienced pain in the dental chair and were able to assess it by visual analogue scale. If asked to characterize the quality of pain most of the children did it from the sensorial aspect, minority of them used the evaluating aspect. The affective aspect was not used at all.

The method used for assessing the children pain proved to be acceptable during normal business hours of the dental department.

It brought the knowledge that - according to our opinion - it is able to enrich paediatric dentistry with new aspects.

This research was supported by Grant Agency Czech Republic, project No. 406/97/0158.

\section{References}

1. Carlsen A, Humphris GM, Lee GT, Birch RH. The effect of pre-treatment enquiries on child dental patients's posttreatment ratings of pain and anxiety. Psychol Health 1993;8:165-74.

2. Mareš J, Hubková V, Skalská H, Ludvíková L. Intenzita dětské bolesti u stomatologických výkonů. In: Mareš J. (Ed.) Dítě a bolest I. (research report). Hradec Králové, LF UK a FN 1995: 62-7.

3. Mareš J, Rybářová M. Dětský strach ze stomatologických výkonů. Prakt Zub Lek 1994;42:186-92.

4. Milgrom P, Weinstein P, Golletz D, Leroux B, Domoto P. Pain management in school-aged children by private and public clinic practice dentists. Pediatr Dent 1994;16:294300.

5. Vassend O. Anxiety, pain and discomfort associated with dental treatment. Behav Res Ther 1993;31:659-68.

Submitted September 1997.

Accepted October 1997.

Doc. PhDr. Jiří Mareš, CSc., Department of Social Medicine, Charles University, Faculty of Medicine, Šimkova 870, 50001 Hradec Králové, Czech Republic. 